\section{Maps as Mediated Seeing: Fundamentals of Cartography}

Written by Gerald Fremlin, with Arthur H. Robinson

Published in 2005 by Trafford Publishing, Victoria, BC, Canada

272 pages, 15 figures, 1 table

$\$ 26.96$ (US) softcover

ISBN 141206682-4

Reviewed by Mary L. Johnson

Technical Writer, Remington \& Vernick Engineers

Haddonfield, New Jersey

www.rve.com

The authors of Maps as Mediated Seeing propose to answer the age-old question, "What is a map?" Yet, the one thing the reader can't help noticing when paging through this book is that there aren't any conventional geographic maps inside. There are a handful of diagrammatic images with varying levels of visual appeal, but no color insets, no fold-outs: no true geographic imagery of any kind, not even on the cover. This seems very strange at first, particularly considering the impressive cartographic backgrounds of the two authors.

Arthur H. Robinson was a Professor of Cartography at the University of Wisconsin, Madison for many years and is perhaps best known as the author of Elements of Cartography. He died in retirement in 2004 at the age of 90. Gerald Fremlin is Canadian, and served in the Royal Canadian Air Force in World War II. He worked on The National Atlas of Canada through the Geographical Branch, Ottawa, ultimately becoming its editor-in-chief. He did graduate work under Arthur $\mathrm{H}$. Robinson in the early 1960s. This book began through that initial association and continued as a post-retirement project for Fremlin, with Robinson providing edits and comments.

The authors are quick to note that many books have been written on what a map is, but these have mostly reflected on the various uses of maps rather than on what constitutes a map itself. A good map is more than just a source of geographical reference. A good map, according to the authors, is a type of trompe-l'oeil art that seeks to trick the viewer's eye into seeing three dimensions where only the one-dimensional paper image actually exists. The objective of map design is to balance detail with legibility in such a way as to enhance that three-dimensional impression while still providing the related annotation and symbology needed to fully portray the area represented. The latter must be done in almost subliminal fashion in order to effectively succeed.

Mediated seeing is defined here as seeing by representation. Watching movies or television, viewing photos, or looking at a map are all versions of medi- ated seeing. We, as the viewers, are not actually experiencing the subjects as we would firsthand, yet we have been drawn in somehow on another plane and provided with a type of firsthand knowledge we could not otherwise have achieved. Those stereotypical "you are here" maps provided in many public parks and tourist destinations are perhaps a perfect example. The viewer becomes part of the surrounding environment and is quickly acclimated, able to "see" if a desired destination is east or west, left or right of where the viewer is standing.

A very important point about mediated seeing has to do with perspective. This is particularly true when we describe an image or representation of a geographic feature to others. If we are looking at a photo of a mountain, for example, we would describe the mountain as being in the picture. However, if we are looking at a map of the same mountain, we would describe the mountain as being on the map. This is because a photo makes us feel as if we are looking at something on the same plane. Our eyes are drawn from foreground to background, as if looking through a window at the world beyond. A map, on the other hand, tends to provide a more three-dimensional representation of an area, and even a virtual sense of altitude. The distance between the eye and the map actually makes it seem as if we are floating over the area portrayed. Hence, the mountain is on the map in the same way it is on the earth below.

Two types of maps are analyzed in this book: topographical maps and thematic maps. Topographical maps offer a truly visual, geographical perspective of an area: whether is it flat or mountainous, wooded or desert, coastal or inland. Thematic maps, on the other hand, show how an area is from more of a non-visual, scientific perspective: whether the climate is hot or cold, whether the population is dense or sparse, or whether regional income is agricultural or industrial in nature. Of the two types, topographical maps are covered first, and in greater detail.

Although all maps tend to be models of the earth to some extent, topographical maps are particularly helpful for defining the surface characteristics of the earth. This can be done through various means, including careful application of symbology and color. Map symbols can be associative, such as using an airplane to represent an airport, or more generic, such as using a small square to represent any kind of building. Annotation is also a very important part of symbology, as it further defines each individual site.

Using color on a map is another means of enhancing the viewer's overall comprehension of the area portrayed, since geographical detail will likely stand out more in color than it will in black and white. Consider the effectiveness of using blue to represent water features on a map rather than shades of black or gray. 
This is true regardless of whether the viewer is looking at the map as a whole or trying to focus on a particular geographic feature.

Lines are also important features on topographical maps. A simple change in line color, line style or line thickness can denote various types of boundaries, geographical contours, or even latitude/longitude information. The effectiveness of contour lines for providing three-dimensional relief imaging is demonstrated in this book not with a geographic map, but with a contoured face derived by photogrammetry. The detail is striking.

Thematic maps are considered "process" maps in that they depict the processes of change. Several categories of thematic maps are briefly presented. Geophysical maps show the processes of change on the planet itself, and include geological and climatological maps. Historical maps show the processes of mankind's exploration or settlement of an area over time. Demographic maps deal with the process of population distribution and its effects on familiar quality-of-life concerns. Economic maps show the processes of change that impact a region's economy, such as income levels, natural resources, and output capacity of various industries. Correlating maps show the relationship process between two or more differing subjects, such as how the amount of annual rainfall relates to crop success in an area.

One important point that consistently comes up in the municipal mapping field I work in is the importance of a good base map foundation for all mapping projects. Maps as Mediated Seeing drives home this point by describing the important relationship between thematic data and the topographical base. In other words, without a good base map to anchor it, thematic data would be reduced to an abstract swirl of colors or an ambiguous set of figures. Conversely, without thematic data, even the best topographical base map would provide only limited information about what an area is really like, since it concentrates solely on terrain and landscape. Our sense of the world is not only visual or even tactile in nature, but built upon other sensory and intellectual information as well. Combining thematic data with a topographical base creates a true "All Senses Map" that allows the viewer to experience things that are not "seeable" in the conventional sense, such as temperature variations, annual rainfall, population densities, and land use. This, too, is a form of mediated seeing.

Thematic maps are further defined and explored later in the book, particularly the use of chloropleths to depict information through gradations of color. The use of pictures and other graphics to enhance a map is also briefly examined from both a positive and negative perspective.

An Afterword provides a brief look at the future of cartography, which is now largely defined by the use of GIS technology. GIS allows the digital cartographer to be more prolific than the traditional mapmaker could ever have imagined. Since GIS is not limited by paper, it can offer incredible opportunities, not the least of which is the ability to easily zoom through multiple map scales in order to examine an area at varying levels of detail. The same regional information that once required an entire atlas to display is now seamlessly available in digital format right at the cartographer's fingertips.

The first and last chapters of the book contain various short essays on mapping subjects that are interesting in and of themselves, but do not otherwise fit into the overall subject matter explored. The book also includes a glossary of terms, a detailed bibliography and a subject index.

I have always felt that mapmaking is as much an art as a science. This theory is corroborated for me whenever I compare two seemingly identical maps of the same location created by two distinct sources. The setting may be shared, but the resulting imagery is seldom alike. The differences between the two may be subtle or they may be extreme, but they are most often reflective of artistic expression. For this reason, I was not surprised that no definitive or encyclopedic answer was provided to the book's opening question, "What is a map?" The authors have instead shared with us their accumulated wisdom, allowing each of us to formulate a satisfactory answer on our own.

As its subtitle suggests, this book examines the fundamentals of cartography and expands upon them in painstaking detail, taking simple ideas that might otherwise be only an afterthought to most readers and transforming them into immensely important principles in the overall process of mapmaking. For example, the intricacies of the legend are carefully explored, and how its composition and application can ultimately enhance or overcomplicate a particular map. The book also has extensive footnotes, and in fact, there are more footnotes than text on some pages, which occasionally makes it difficult to follow.

I would not recommend this book for anyone without a serious interest in cartography and all its aspects. In the book's Acknowledgements section, it is noted that Maps as Mediated Seeing was originally published in the journal of the Canadian Association of Cartographers [sic, Canadian Cartographic Association] in 1999, and was considered by many "a hard read." Considerable work and editing was performed to make it "a little more user-friendly," but it is still a very intense read. This is not the sort of book that the reader could simply glance through at leisure or pick up in the middle with very much success. Each new chapter naturally follows and builds upon the previous chapter, bringing the reader systematically to the 
crux of the subject just as successive contour lines on a topographical map will ultimately bring the viewer to the apex of the summit. For those readers who are prepared for the climb, it is a journey well worth taking.

\section{Seeing Through Maps: Many Ways to See the World} Written by Denis Wood, Ward L. Kaiser and Bob Abramms

Published in 2001, 2005, 2006 by ODT, Inc., Amherst, MA. 152 pages, 78 illustrations and Appendix of Map Projections. \$24.95 (US) softcover

ISBN 978-1-931057-20-2

\section{Many Ways to See the World (Companion DVD)}

By Dr. Bob Abramms

Published in 2006 by ODT, Inc., Amherst, MA

30 minutes, 70 PowerPoint images

$\$ 89.95$ for institutions, including reproduction rights $\$ 39.95$ for individual use

www.odt.org

Reviewed by Mary L. Johnson

Technical Writer, Remington E Vernick Engineers

Haddonfield, New Jersey

www.rve.com

ODT, the publisher of Seeing Through Maps, has a mission that includes "teaching people to see the world from a broader, more inclusive perspective."

This book, and the team of authors responsible for it, attempts to do just that in regard to world maps and related imagery.

Denis Wood is a writer/artist and social scientist with a keen interest in maps. He is the author of The Power of Maps, as well as numerous articles on a variety of socially relevant subjects. Ward L. Kaiser is a publisher, pastor, teacher and community organizer. He introduced the Peters Projection to North America by publishing its first English language version in 1983.

Dr. Bob Abramms is an expert on management training and executive development programs. He has conducted seminars on "Managing Cultural Differences" for a wide variety of clients. His companion DVD, "Many Ways to See the World," is based on imagery from Seeing Through Maps. The DVD is offered separately at an additional cost and is discussed later in this review.

The book Seeing Through Maps begins by briefly examining the concept of truth in our daily lives. To a large extent, truth depends on a person's point of view. For example, two people having lunch together will not experience the meal exactly the same way, since they are looking at it, literally, from opposite sides of the same table. One person is looking in one direction, and one person in another, so, although they are together for the same meal, they are having different experiences because of their unique vantage points. Truth as it applies to mapping is similar in nature. Whether we consider a map "good" or "truthful" generally depends on our point of view.

All maps have a purpose. The overall look and quality of each map is related to its purpose. The original purpose for the Mercator Projection in 1569 was clearly stated on the map: "A new and Enlarged Description of the Earth with Corrections for Use in Navigation." The Mercator was created to show places in relation to one another, not necessarily accurately in all respects, but correct for sailing purposes. The Mercator makes the latitude and longitude lines, and lines of constant bearing used by sailors, straight, so they can be used to chart courses and guide sailors across vast oceans. By this definition, the Mercator Projection was a great success, and can still be used for navigational purposes today. But is it a "politically correct" map?

The Mercator Projection is considered the most recognized of all world maps, mostly because it has been around for such a long time and was so well thought of by European navigators. However, the Mercator is well known today for its distortion of size, particularly near the poles. Its depiction of an enormous Greenland is a prime example. In fact, the Mercator has been perceived as purposely distorting land size in favor of the Northern Hemisphere, which takes up a disproportionate percentage of the map's overall display area. In particular, the Mercator has been perceived as distorting land size in favor of the Colonial Powers, by making the continents of North America and Europe seem much larger in relation to the rest of the world than they actually are.

In 1974, Arno Peters introduced the Peters Projection, a version of the world map that shows countries and portions thereof in more correct size perspective. The latitude and longitude lines are still straight, as they are on the Mercator Projection, but the size relationships between countries are less distorted. For that reason, the Peters Projection is seen as a more fair depiction of countries in the Equitorial regions. However, the Peters Projection noticeably distorts the familiar shape of each land area, making some continents appear stretched and elongated.

Several unusual and intriguing views of the world are presented on the pages that follow this discussion, including a map centered on the City of Toronto. At first glance, it appears that the reader is looking down at a section of the Earth from high above, with Toronto, Canada at the center of the sphere, and what appear to be "latitude" lines moving outward from Toronto like ripples on a pond (these lines are actually 